\title{
Distal Thigh Compression Garment Improves Female Athlete Knee Control and Sports Movement Safety Perceptions
}

\author{
D. Boschert ${ }^{1}$, J. Nyland ${ }^{1}$, J. Matsuno ${ }^{1}$, S. Pletz ${ }^{1}$, W. Polio ${ }^{2}$ \\ 1 MSAT Program, Kosair Charities College of Health and Natural Sciences, Spalding University \\ Louisville, Kentucky, USA \\ 2 Department of Orthopaedic Surgery, University of Louisville, Louisville, KY, USA
}

\section{CORRESPONDING AUTHOR:}

John Nyland

Kosair Charities College of Health and Natural Sciences

Spalding University

901 South 4th Street

Louisville, KY 40203

Phone: 502-873-4224

E-mail: jnyland@spalding.edu

DOI:

10.32098/mltj.01.2020.08

LEVEL OF EVIDENCE: 2B

\begin{abstract}
SUMMARY
Introduction. This study measured knee frontal plane projection angle (FPPA) and sports safety and performance perceptions of female athletes during a single leg forward hop down and stabilization (SLFHS) for 3 conditions (standard knee sleeve, no device and distal thigh compression garment (DTCG)). The hypothesis was that the DTCG group would display superior dynamic knee valgus FPPA compared to the standard knee sleeve and no device groups.

Methods. Eighteen healthy college athletes participated in this prospective cohort study with a randomized device order. FPPA was measured during SLFHS using two-dimensional biomechanical techniques to estimate dynamic knee valgus loading. A $10-\mathrm{cm}$ visual analog scale survey collected data regarding subject perceived knee control, sports movement capability and overall satisfaction for each condition. Pearson correlations delineated knee valgus, safety and performance relationship perceptions $(\mathrm{p}<0.05)$.

Results. Mean/maximum dynamic knee valgus FPPA was lowest during the DTCG condition $\left(8.7 \pm 6^{\circ} / 12.2 \pm 7^{\circ}\right)$, or a $19.4 \% / 21.3 \%$ range of motion reduction compared to the standard knee sleeve $\left(10.8 \pm 7^{\circ} / 15.5 \pm 8^{\circ}\right)$ and a $21.6 \% / 17 \%$ reduction compared to the no device $(11.1$ $\left.\pm 7^{\circ} / 14.7 \pm 7^{\circ}\right)$ conditions. Chi-square tests revealed that the T:25 group displayed a greater proportion of subjects with a " 1 " score ( $\leq$ threshold value) than the standard knee brace or no device groups for both mean (one-sided $\mathrm{p}$ value $=0.02$ ) and maximal (one-side $\mathrm{p}$ value $=0.049$ FPPA). In relationship to maximum dynamic knee valgus FPPA, the DTCG was the best overall condition $(\mathrm{r}=0.61, \mathrm{p}=0.007)$, relating more strongly to perceived knee control $(\mathrm{r}=0.63, \mathrm{p}$ $=0.005)$ and sports movement capability $(\mathrm{r}=0.64, \mathrm{p}=0.004)$.

Conclusions. Compared to standard knee sleeve and no knee device conditions, the T:25 device provided better dynamic knee valgus FPPA control and stronger subject perceptions of best overall condition, knee control and sports movement capability.
\end{abstract}

KEY WORDS

Anterior cruciate ligament; injury prevention; knee bracing

\section{INTRODUCTION}

Poorly controlled dynamic knee valgus (frontal plane knee motion) during activities greatly increases non-contact knee injury risk, particularly among athletic girls and women (1-3). The combination of poorly controlled, hip adduction-internal rotation and knee abduction that occurs with the sudden single leg loading of many athletic maneuvers can transmit injurious loads to the medial collateral ligament, medial meniscus, and anterior cruciate ligament and may also contribute to lateral patello-femoral joint disloca- tion (1-3). Previous studies have evaluated how knee brace or sleeve use can help prevent knee injury (5-8). These studies have evaluated the influence of knee sleeve or brace use on standing balance, coordination, proprioception, and ground reaction forces (5-8). Little is currently known about the influence of knee brace or sleeve use on dynamic knee valgus during sports task performance.

Prophylactic knee bracing may help decrease subsequent knee injury frequency and severity during collision injury mechanisms in sports such as downhill skiing (9). However, 
prophylactic knee braces are also known to alter knee joint kinematics and lower extremity neuromuscular activation patterns (10-12) and supportive efficacy evidence is limited (2). Extraneous brace movement during athletic performance can make fit maintenance difficult, leading to poor device function and reduced wear compliance. Properly fit thigh compression sleeve or garment-based devices may provide greater comfort and less extraneous movement than strap-based devices which attempt to approximate the knee joint center with the axes of collateral hinges. Additionally, they do not provide the same level of rigid support. Athletes who are predominantly at risk for non-contact knee injuries may benefit from a thigh compression sleeve device that controls frontal plane knee motion without compromising athletic movement capability.

A distal thigh compression garment (DTCG) may enhance frontal plane dynamic knee stability through enhanced medial quadriceps femoris, medial hamstring and iliotibial tract-fascia lata function $(13,14)$. The T:25 device (CEP Topical Gear, Whitsett, NC, USA) is a DTCG designed with two buttress pads positioned over the medial quadriceps femoris and the medial hamstring muscle groups to improve dynamic knee stability through enhanced neuromuscular control (figure 1) (15). The purpose of this prospective cohort study with randomized device order was to evaluate subject dynamic knee valgus frontal plane projection angle (FPPA) (16) and perceptions of sport performance and injury prevention capability during a single leg forward hop down and stabilization (SLFHS) task under three conditions (DTCG, standard knee sleeve (Procare Knee Support, DJO, LLC, Vista, CA, USA), and no sleeve at all. The hypothesis was that the DTCG group would display superior dynamic knee valgus FPPA and perceptions of sports performance and injury prevention capability compared to the standard knee sleeve and no device groups.

\section{MATERIALS AND METHODS}

\section{Participants}

University Research and Ethics Committee approval was sought and obtained. Subjects were recruited through university email carrying an electronic flyer with study information and through contact with the university coaching and athletic training staffs. All subjects that met study inclusion criteria and agreed to study participation signed a written consent. Eighteen subjects agreed to study participation. Inclusion criteria required that subjects were active university women athletic team members. Subjects were required

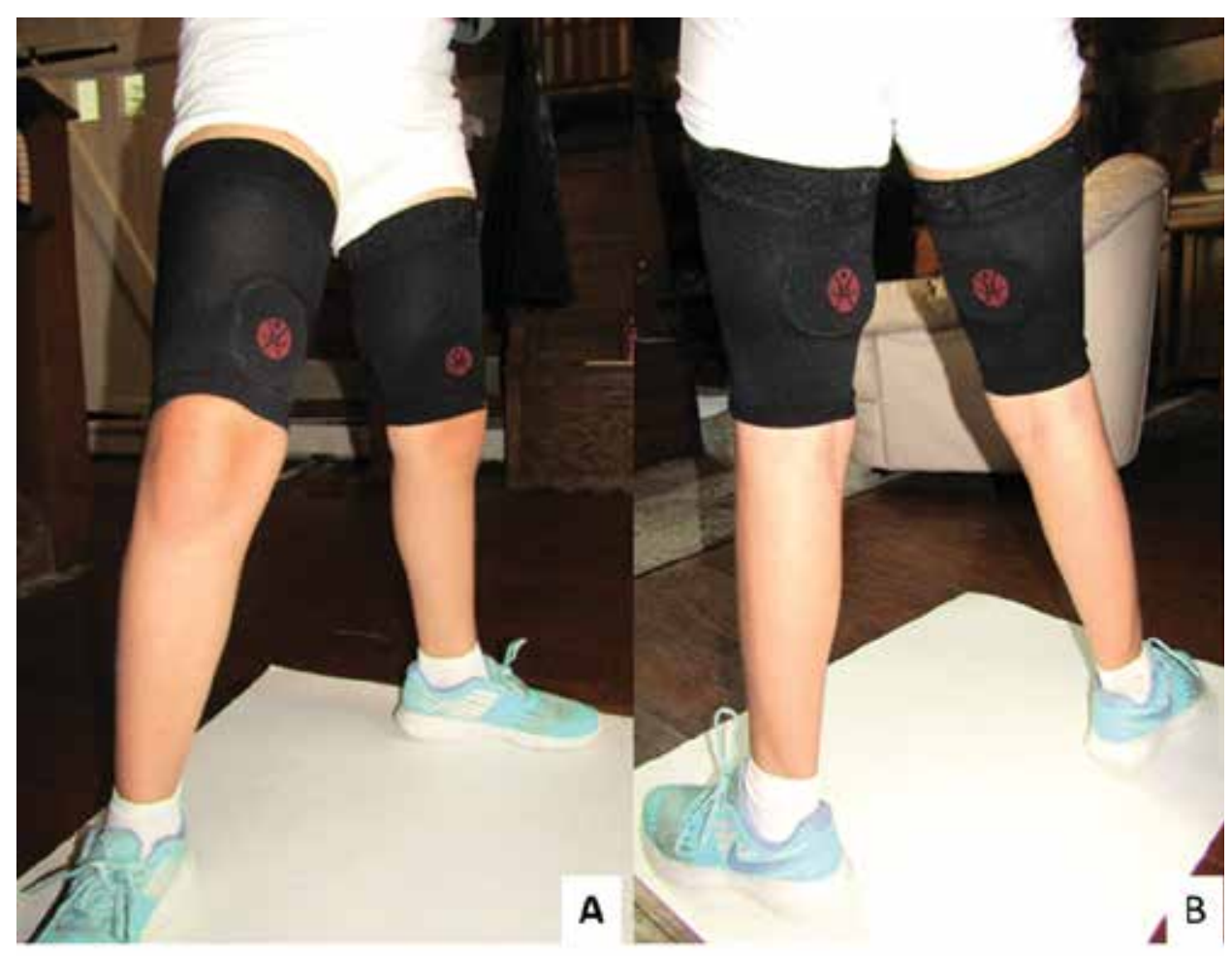

Figure 1. The DTCG group wore the T:25 device (CEP Topical Gear, Whitsett, NC, USA) (A) front, (B) back. 
to be $\geq 18$ years and could not have any knee injury history or current lower limb injuries. All subjects were healthy and between 18-22 years of age. Height ranged from $162-176 \mathrm{~cm}$ with a $166.7 \mathrm{~cm}$ mean. Weight ranged from $54.4-104.3 \mathrm{~kg}$ with a $75.6 \mathrm{~kg}$ mean. Six soccer players, 5 softball players, 3 basketball players, 3 volleyball players, and 1 track and field athlete participated in this study.

\section{Two-dimensional kinematic data collection}

Testing took place in the university athletic training laboratory. Subjects wore low top athletic shoes and snug fitting running shorts and tops during testing. Following a 10 minutes warm-up riding a stationary bicycle at a comfortable intensity and volitional stretching, subjects were instructed in SLFHS task performance from a $30.5 \mathrm{~cm}$ tall step. The dominant lower extremity was defined as the side that subjects preferred to use when kicking a soccer ball. While standing on the step, subjects were instructed to lift their non-dominant leg from the step and perform a forward hop down while landing with a flexed knee, while maintaining the landing position for three seconds. After performing 3 practice trials, retro-reflective markers were applied $13 \mathrm{~cm}$ distal to the anterior superior iliac spine (approximately anterior hip joint center), over the center of the patella (approximately knee joint center), and at the anterior leg $13 \mathrm{~cm}$ proximal to the medial malleolus (approximately lower leg sock line). Prior to data collection, subjects selected a sealed envelope that contained a device use order list. Following this, 3 SLFHS test trials were performed for each condition using the dominant lower extremity. A digital camera $(120 \mathrm{~Hz})$ (IPAD, Apple Inc., Cupertino, CA, USA) positioned $1.83 \mathrm{~m}$ from the step base and two-dimensional kinematic analysis software (Hudl, Agile Sports Technologies, IA, USA) were used to evaluate knee FPPA alignment during relaxed single leg stance and following ground impact. Both mean and maximal dynamic FPPA magnitudes were analyzed. Pilot testing revealed intraclass correlation coefficients of 0.91 and 0.89 for static and dynamic knee FPPA measurements, respectively, indicating very good measurement reliability (17). Subjects completed the perceived knee function survey immediately following task completion for each condition.

\section{Perceived Knee Function Survey}

Subjects completed several 10-cm visual analog scale (VAS) survey questions about their perception of the best overall condition, best knee control condition and best sports movement capability condition. The survey was modified from sports or exercise-induced symptom surveys (18-20).
With end range descriptors of Strongly Agree and Strongly Disagree subjects responded to the following statements after completing each test condition: this condition provides better knee control; this condition best enables sports movements; and this condition is best overall. The survey was piloted tested for clarity and understanding on an age and gender matched group of college student-athletes prior to study use.

\section{Statistical analysis}

A priori statistical power analysis revealed than a minimum of 10 subjects would be needed to identify a $2^{\circ}$ knee FPPA change at a beta error level of $80 \%$ and an alpha level of $\mathrm{p}<$ 0.05 . Statistical analysis was performed using SPSS version 24.0 software (IBM-SPSS, Armonk, NY). An alpha level of $\mathrm{P}<0.05$ was selected to indicate statistical significance. A Kolmogorov-Smirnov Test revealed that data displayed normal dynamic knee valgus FPPA and survey response distributions. Based on overall cohort performance and the report of Jones et al (16), the mean FPPA threshold of good dynamic knee valgus control was set at $10^{\circ}$ and the maximum FPPA threshold of good dynamic knee valgus control was set at $14^{\circ}$. Based upon these threshold values, subjects in each group were classified either as displaying a knee FPPA that was $\leq$ each threshold angle $(=1)$ or $>$ each threshold angle $(=2)$. Following these classifications, Chi-Square tests were used to compare the proportion of subjects within each group that were assigned a score of 1 for mean or maximum knee FPPA. Pearson product moment correlations were used to determine relationship strength between dynamic knee valgus during SLFHS task performance and subject perceptions of condition-specific sports performance capability and knee safety.

\section{RESULTS}

Mean/maximum dynamic knee valgus FPPA was lowest during the DTCG condition $\left(8.7 \pm 6^{\circ} / 12.2 \pm 7^{\circ}\right)$, or a $19.4 \% / 21.3 \%$ range of motion reduction compared to the standard knee sleeve $\left(10.8 \pm 7^{\circ} / 15.5 \pm 8^{\circ}\right)$ and a $21.6 \% / 17 \%$ reduction compared to the no device (11.1 $\left.\pm 7^{\circ} / 14.7 \pm 7^{\circ}\right)$ conditions. Chi-square tests revealed that the T:25 group displayed a greater proportion of subjects with a " 1 " score than the standard knee brace or no device groups for both mean (one-sided p value $=0.02$ ) and maximal (one-side p value $=0.049$ ) dynamic knee valgus FPPA (figure 2). Perceived Knee Function Survey results are presented in figure 3. Statistically significant differences were not evident with the exception of the knee sleeve condition which was scored the best overall condi- 


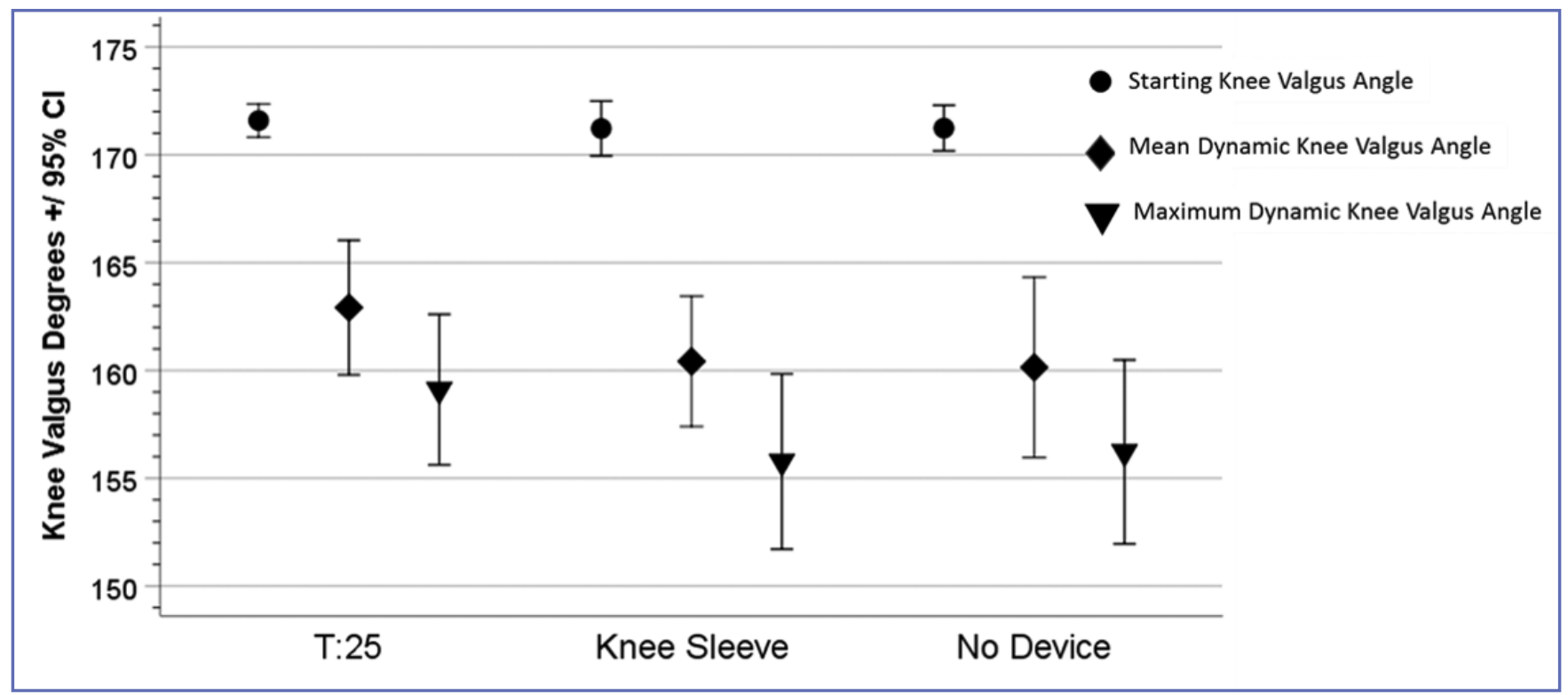

Figure 2. Chi-square tests revealed that the T:25 group displayed a greater proportion of subjects with a "1" score than the standard knee brace or no device groups for both mean $\left(\leq 10^{\circ}\right.$, one-sided $p$ value $\left.=0.02\right)$ and maximal $\left(\leq 14^{\circ}\right.$, one-sided $p$ value $=0.049$ ).

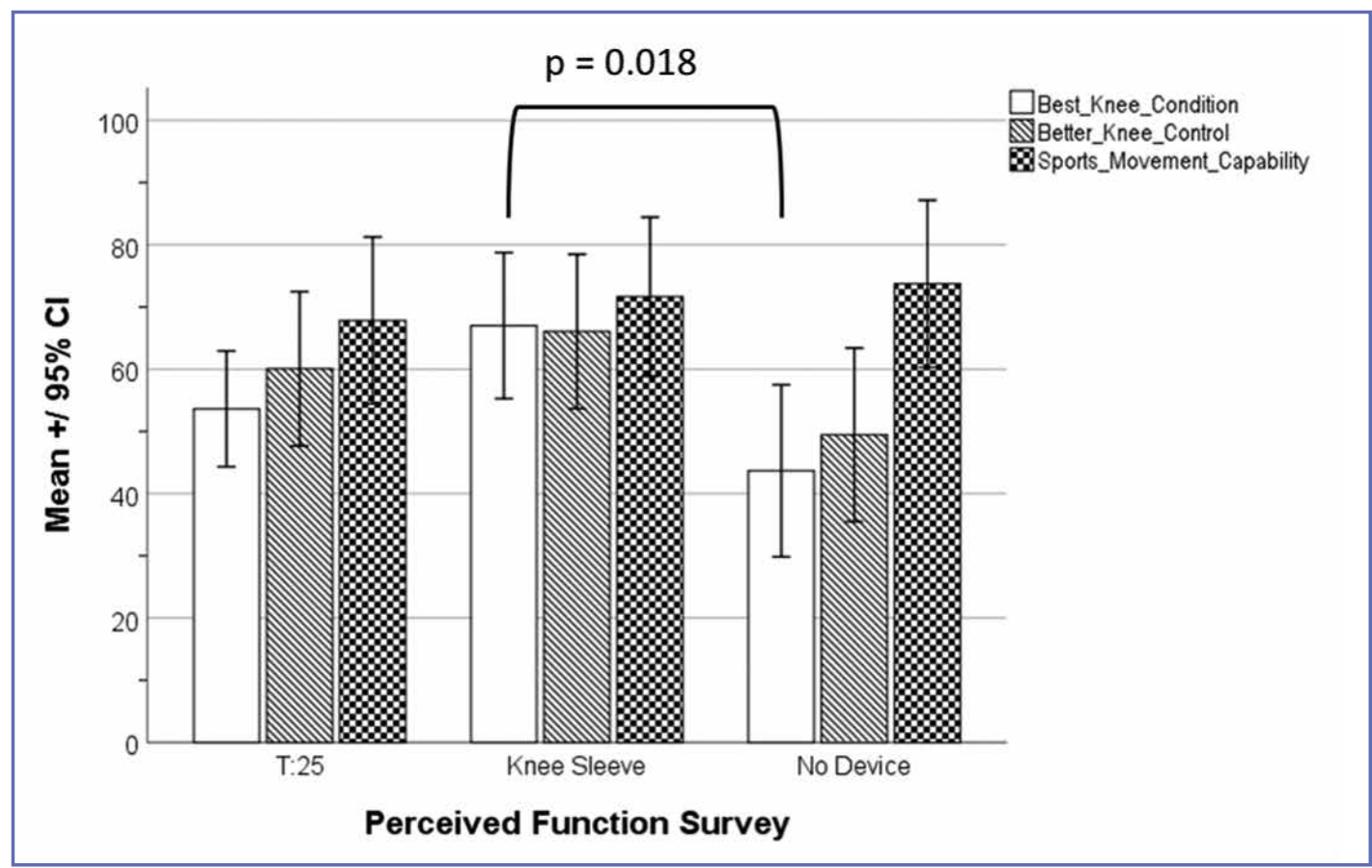

Figure 3. Perceived knee function survey data only revealed statistically significant group differences for the knee sleeve condition being superior to the no device condition. 
tion compared to the no device condition. The only condition that displayed a statistically significant relationship between maximum or mean dynamic knee valgus FPPA during SLFHS, perceived best overall condition, best knee control, and best sports movement capability was the DTCG group (17). In relationship to both maximum and mean dynamic knee valgus FPPA values during SLFHS

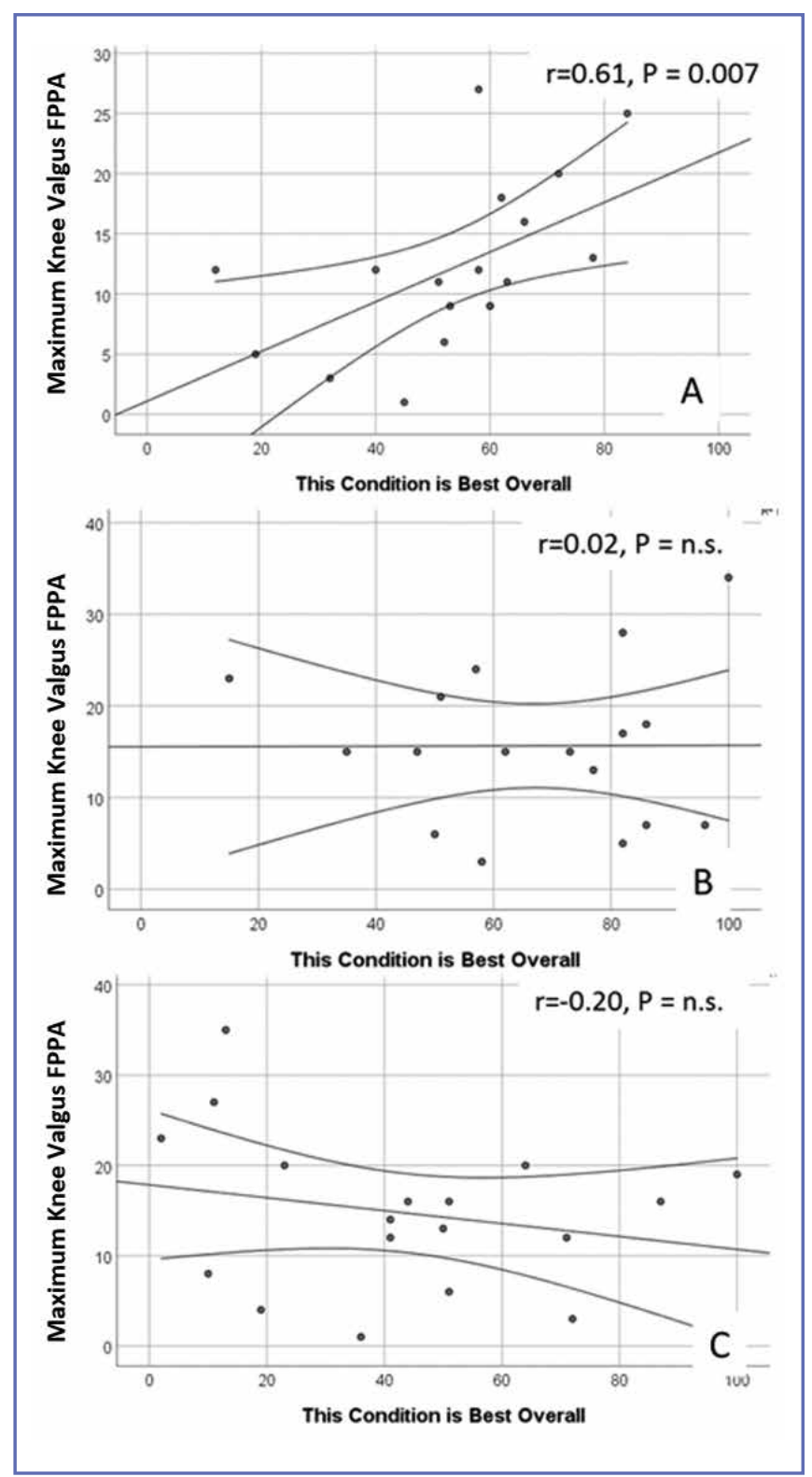

Figure 4. The DTCG (T:25) was the only condition that displayed a significant relationship between maximum dynamic knee valgus FPPA during SLFHS and subject perceptions of the best overall condition $(A)(r=0.61, P=0.007) ;(B)$ standard knee sleeve; (C) no device. performance subjects perceived DTCG use as the best overall condition $(\mathrm{r}=0.61, \mathrm{P}=0.007 / \mathrm{r}=0.42, \mathrm{p}=0.04)$ (figure 4) to be more strongly related to sports movement capability $(\mathrm{r}=0.64, \mathrm{p}=0.004 / \mathrm{r}=0.53, \mathrm{p}=0.01)($ figure 5) and to perceived knee control $(r=0.63, p=0.005 / r=0.46$, $\mathrm{p}=0.03)$ (figure 6) than either the standard knee brace or no device conditions.

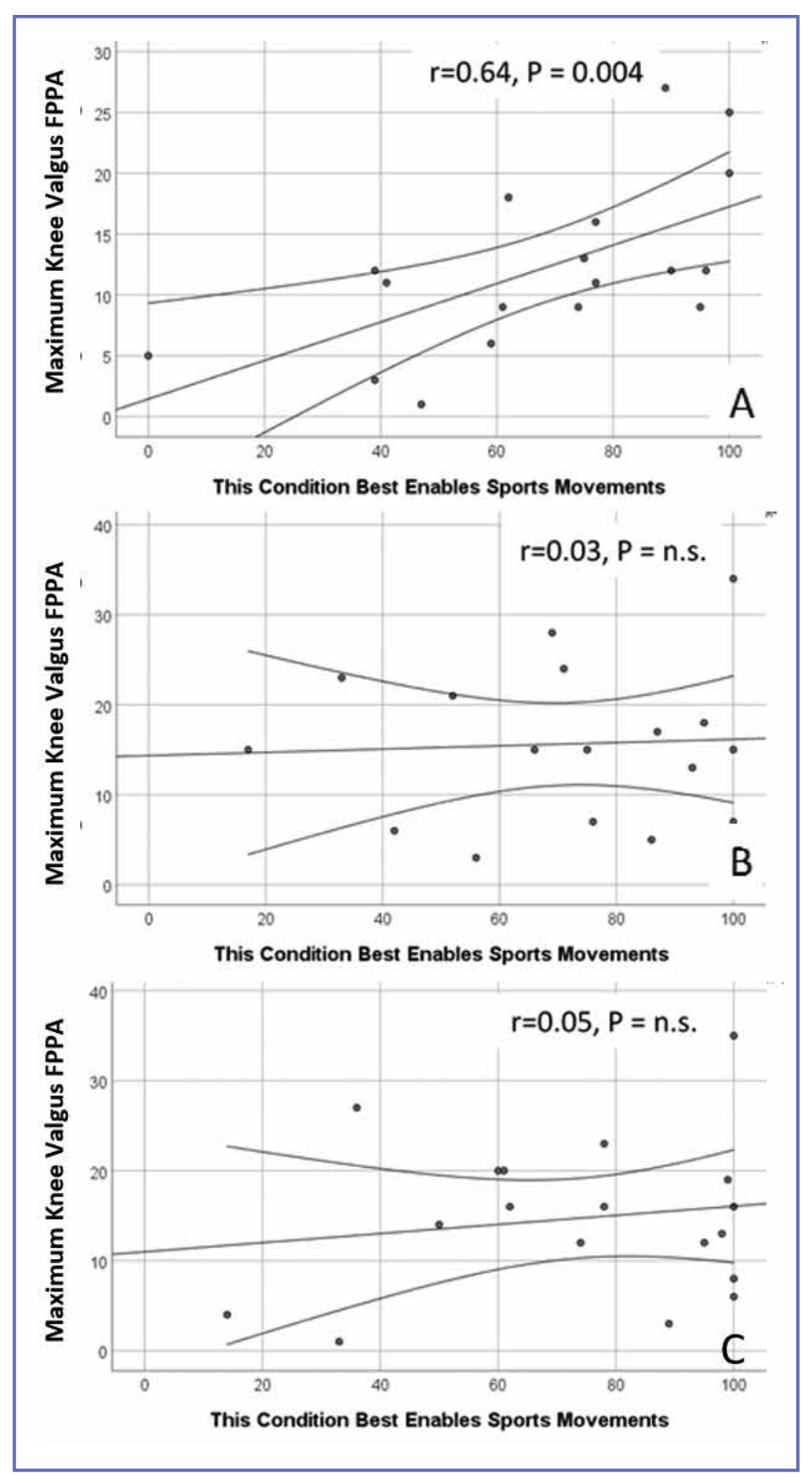

Figure 5. The DTCG (T:25) was the only condition that displayed a significant relationship between maximum dynamic knee valgus FPPA during SLFHS and subject perceptions of the condition that best enabled sports movements $(A)$ $(r=0.64, p=0.004)$; $(B)$ standard knee sleeve; $(C)$ no device. 


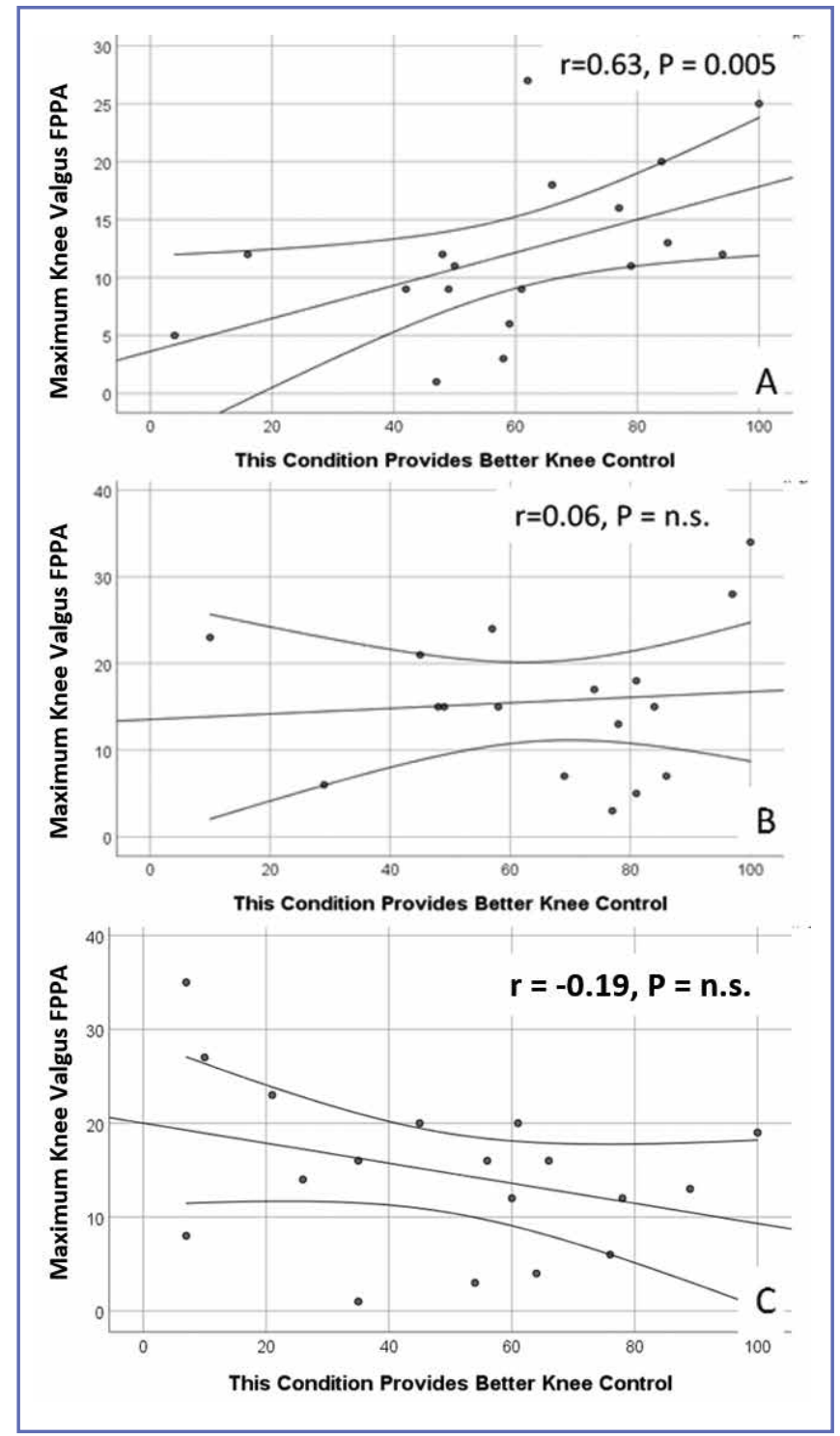

Figure 6. The DTCG $(\mathrm{T}: 25)$ was the only condition that displayed a significant relationship between maximum dynamic knee valgus FPPA during SLFHS and subject perceptions of the condition that provided better knee control $(A)(r$ $=0.63, p=0.005) ;(B)$ standard knee sleeve; $(C)$ no device.

\section{DISCUSSION}

The most important study finding was that most subjects had their lowest mean and maximum dynamic knee valgus FPPA during SLFHS performance with DTCG use. Secondly, DTCG use was the only condition that displayed significant mean and maximum dynamic knee valgus FPPA and perceived best overall condition, knee control and sports movement capability relationships. These findings provide both objective and subjective evidence that T:25 garment use provided superior dynamic knee valgus FPPA control during SLFHS task performance compared to standard knee sleeve or no device use.

The efficacy of prophylactic knee brace use (table I) and functional brace use post-ACL reconstruction (table II) remains questionable. Regarding prophylactic braces, several studies have shown that in comparison to non-braced conditions, brace use better controlled knee kinematics during single leg hop, cut, pivot and jump landing tasks (6,21-23). Some studies have also reported improved knee proprioception $(5,24)$, while others did not observe improved proprioception compared to non-braced conditions $(7,25)$. Some studies have also reported improved knee kinetics during hop landings or at least knee kinetics that did not compromise performance $(26,27)$. However, others have reported altered knee kinematics and neuromuscular activation patterns with brace use (11). Some have concluded that if brace migration or movement is negligible then prophylactic knee brace use does not adversely influence running speed or agility $(10,28)$. When the outcome variable focuses exclusively on injury prevention several studies reported increased (29-31) rather than decreased knee injury rates and one specifically mentioned fear of decreased performance adversely influencing brace use compliance (32).

For functional knee brace use post-ACL reconstruction, several studies have supported their potentially positive influences on knee kinematics, particularly lower leg rotational control (33-36), while others have supported their use for improving hop distance symmetry, but not landing mechanics symmetry (37). Their use, however, does not appear to improve clinical outcomes $(38,39)$. When focusing solely on re-injury rates or secondary prevention following ACL reconstruction, supportive knee brace use efficacy could not be identified (40) and some suggest that avoiding their use better achieves improved subjective patient outcomes and reduced failure rates as defined by instability, stiffness or persistent pain (41).

Whether evaluating prophylactic or post-ACL reconstruction knee braces, two major considerations become evident. In controlled laboratory settings many braces display lower extremity kinematic control characteristics that suggest a potential capacity for knee ligament protection. However, when injury or re-injury rate reductions are the outcome variable, neither knee brace type displays strong efficacy. Traditional brace use for the purpose of contact or collision knee injury prevention has led to the development of more rigid designs, which rely on tight circumferential strapping to secure proper knee joint alignment. To date, little evidence supports this purpose. A current opinion report suggested that compression from functional knee brace 
Table 1. Prophylactic Knee Bracing (VJ = vertical jump, GRF = ground reaction force, PF = patellofemoral, LE = lower extremity, IR = internal rotation, ER = external rotation).

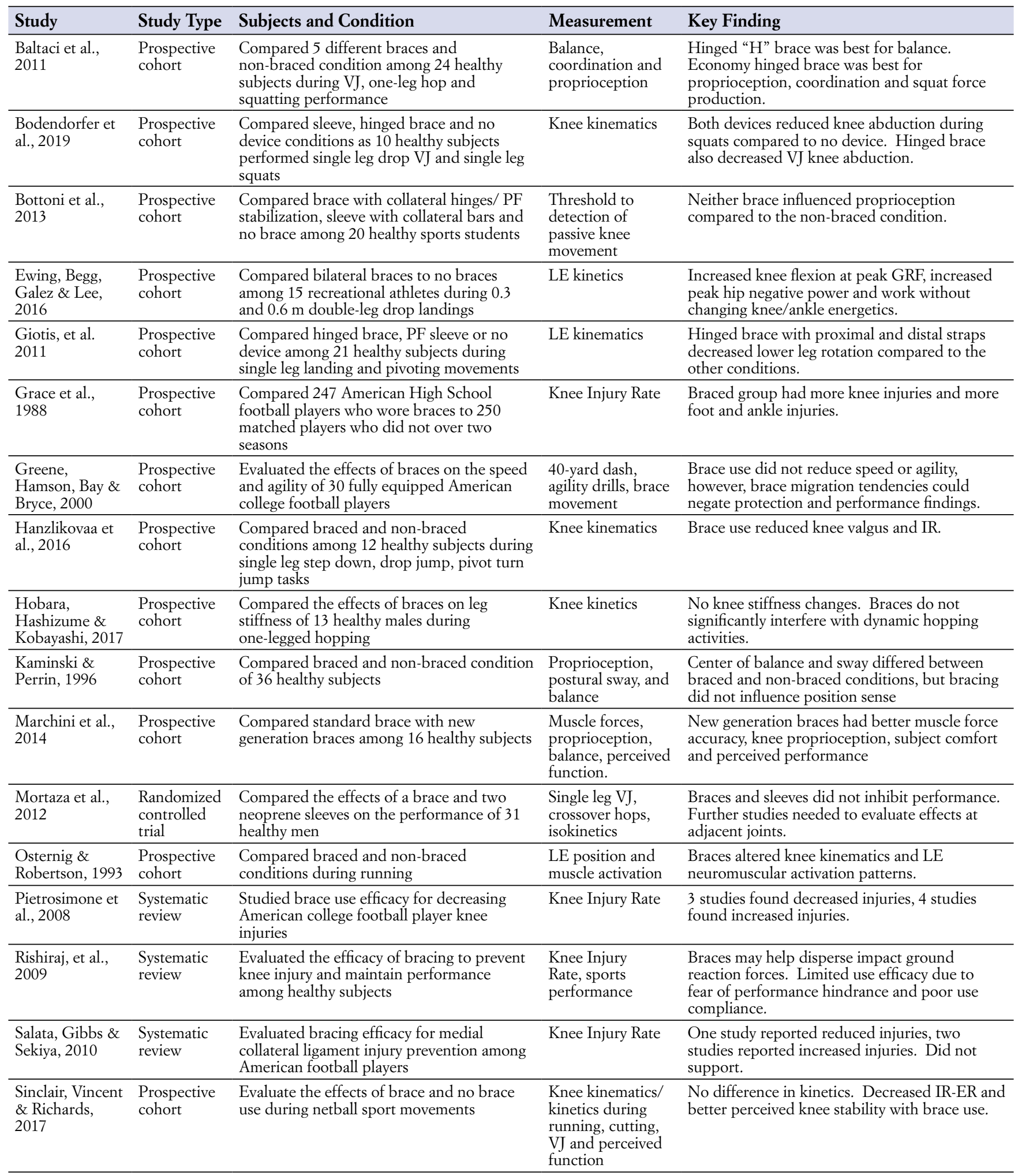


Table 2. Post-ACL reconstruction brace use.

\begin{tabular}{|c|c|c|c|c|}
\hline Study & Study Type & Subjects and Condition & Measurement & Key Finding \\
\hline Giotis et al., 2016 & $\begin{array}{l}\text { Prospective } \\
\text { cohort }\end{array}$ & $\begin{array}{l}\text { Compared brace use, PF sleeve use, and no } \\
\text { device among } 20 \text { men post-HS autograft } \\
\text { ACL reconstruction during two-legged } \\
\text { jump lading from a platform and pivoting } \\
\text { on one foot }\end{array}$ & Lower leg rotation & $\begin{array}{l}\text { Although not as good as at non-surgical } \\
\text { knee, both brace and sleeve decreased } \\
\text { excessive tibial rotation }\end{array}$ \\
\hline Giotis et al., 2013 & $\begin{array}{l}\text { Prospective } \\
\text { cohort }\end{array}$ & $\begin{array}{l}\text { Compared brace use, PF sleeve use, and no } \\
\text { device among } 20 \text { men post-BPTB autograft } \\
\text { ACL reconstruction during two-legged } \\
\text { jump landing from a platform and pivoting } \\
\text { on one foot }\end{array}$ & Lower leg rotation & $\begin{array}{l}\text { Although not as good as at non-surgical } \\
\text { knee, both brace and sleeve decreased } \\
\text { excessive tibial rotation }\end{array}$ \\
\hline $\begin{array}{l}\text { Hanzlikova, } \\
\text { Richards, Hebert- } \\
\text { Losier \& Smekal, } \\
2019\end{array}$ & $\begin{array}{l}\text { Prospective } \\
\text { cohort }\end{array}$ & $\begin{array}{l}\text { Compared proprioceptive knee brace } \\
\text { compared to no brace among } 15 \text { subjects } \\
\text { at } 2-10 \text { years post-ACL reconstruction }(8 \\
\text { BPTB, } 5 \text { HT autograft, } 2 \text { allograft) during a } \\
\text { pivot turn jump and single leg drop tasks }\end{array}$ & Knee kinematics & $\begin{array}{l}\text { Brace use reduced peak knee external } \\
\text { rotation and total transverse plane range } \\
\text { of motion and increased maximum knee } \\
\text { flexion angular velocity. Most subjects } \\
\text { perceived easier task performance with } \\
\text { brace use }\end{array}$ \\
\hline $\begin{array}{l}\text { Martinek \& } \\
\text { Friederich, } 1999\end{array}$ & Meta-analysis & $\begin{array}{l}\text { Compared experimental and clinical } \\
\text { efficacy of brace use to prevent re-injury } \\
\text { following ACL reconstruction }\end{array}$ & Knee Re-injury Rates & $\begin{array}{l}\text { Could not identify supportive efficacy } \\
\text { for post-surgical knee brace use }\end{array}$ \\
\hline $\begin{array}{l}\text { Naik, Das \& } \\
\text { Kamat, } 2019\end{array}$ & $\begin{array}{l}\text { Retrospective } \\
\text { cohort }\end{array}$ & $\begin{array}{l}\text { Evaluated the functional outcome of } \\
32 \text { consecutive patients between } 3-12 \\
\text { months post-ACL reconstruction using HS } \\
\text { autograft and no braces. }\end{array}$ & $\begin{array}{l}\text { Lysholm knee score, } \\
\text { failure rates }\end{array}$ & $\begin{array}{l}\text { Mean Lysholm knee score improved } \\
\text { from } 88 \text { at } 6 \text { months to } 91 \text { at } 12 \text { months. } \\
\text { Avoidance of bracing prevents ACL graft } \\
\text { re-rupture. }\end{array}$ \\
\hline $\begin{array}{l}\text { Peebles, Miller, } \\
\text { Moskal \& Queen. } \\
2019\end{array}$ & $\begin{array}{l}\text { Prospective } \\
\text { cohort }\end{array}$ & $\begin{array}{l}\text { Compared hop testing symmetry of } 28 \\
\text { patients post-ACL reconstruction after } \\
\text { being released to sport and again } 3 \text { months } \\
\text { later with and without knee brace use. }\end{array}$ & $\begin{array}{l}\text { Kinetics, LSI, single, } \\
\text { triple and crossover } \\
\text { hop for distance. }\end{array}$ & $\begin{array}{l}\text { Brace use improved hop distance } \\
\text { symmetry during the early return to } \\
\text { sport period, however, asymmetrical } \\
\text { loading mechanics persist. }\end{array}$ \\
\hline
\end{tabular}

use abnormally elevates thigh and leg intramuscular pressure beneath knee brace straps decreasing blood flow and muscular oxygenation, inducing pre-mature fatigue, impairing muscle function and decreasing performance (12).

The T:25 was better at controlling mean and maximum knee FPPA (dynamic valgus) than a standard knee sleeve or no device. Additionally, T:25 use was the only condition tested that displayed a significant relationship between mean or maximum dynamic knee valgus FPPA and subject perceptions of its use being the best overall condition, best for sports movement capability, and best for knee control. Significant relationships between these variables were not observed for the standard knee sleeve and no device condi- tions. Study findings suggest that T:25 sleeve use may help prevent the dynamic knee valgus that is highly related to non-contact injuries among female athletes (4).

The T:25 manufacturer suggests that localized pressure provided by oval-shaped buttress pads positioned over the medial quadriceps femoris and medial hamstring muscle groups enhances the neuromuscular activation that improves dynamic frontal plane knee stability (15). Since the current study did not include electromyographic analysis, we cannot support or deny this premise. However, the extensive gluteus maximus muscle insertion to the iliotibial tract suggests that it functions as its tendon of insertion in transferring hip region forces to the lower leg (14). Given the powerful hip 
joint extension and external rotational forces generated by the upper gluteus maximus (13) through the femur proximally and distally through lateral tibia abduction-external rotational forces, one can better appreciate its capacity to resist excessive or poorly timed dynamic knee valgus loading. In addition to any direct neuromuscular effects generated through medial quadriceps femoris and medial hamstring muscle group activation, the compressive forces generated across the iliotibial tract and fascia lata proximal to the knee joint likely improves gluteus maximus muscle activation efficiency, kinesthetic acuity, or both. Further studies are needed with other sports and athlete populations who are at high non-contact knee injury risk such as soccer, team handball, basketball and tennis.

There is a growing understanding and appreciation for fascial system linkages through the thoracodorsal fascia, iliotibial tract, fascia lata and quadriceps tendon $(14,42)$ with dynamic intersegmental contributions from powerful gluteus maximus (43) and latissimus dorsi muscles. Rehabilitation clinicians continue to search for innovative ways to decrease knee injury risk without the over constraint from rigid knee braces that creates maladaptive primary or adjacent joint compensations, increased discomfort, decreased performance and reduced use compliance. Subjective athlete perceptions of the T:25 suggests that use compliance would likely be good. Devices such as the T:25 may represent the threshold of a significant shift in protective and performance enhancing knee protective device development (24).

\section{Limitations}

This study is limited in that kinetic evaluation of lower extremity joint moments and electromyographic evaluation of neuromuscular activation patterns were not performed. Further studies are needed to evaluate these important factors. Another limitation was that we did not

\section{REFERENCES}

1. Hewett TE, Myer GD, Ford KR. Decrease in neuromuscular control about the knee with maturation in female athletes. $J$ Bone Joint Surg Am 2004; 86:1601-1608.

2. Logerstedt DS, Scalzitti D, Risberg MA, Engebretsen L, Webster KE, Feller J, Snyder-Mackler L, Axe MJ, McDonough CM. Knee stability and movement coordination impairments: Knee ligament sprain revision 2017. J Orthop Sports Phys Ther 2017;47:A1-A47.

3. Powers CM, Ghoddosi N, Straub RK, Khayambashi K. Hip strength as a predictor of ankle sprains in male soccer players: A prospective study. J Athl Train 2017; 52:1048-1055. control for menstrual cycle phase which is known to influence female athlete ACL injury risk (44). However, each subject performed each condition in a randomized assignment order, thereby controlling for this possible confounder. These factors withstanding, study findings based on kinematic and subject perception data provide encouraging results. Non-contact knee injuries in all athletes, but particularly among females are known to be associated with excessive, or poorly controlled frontal plane knee motion $(1,3,4,45)$. Although compression garment use above the knee has not been found to improve proprioception through dynamometer target angle position tests, these findings likely differ considerably from the knee joint neuromuscular control demands associated with functional movements (46). Most knee ligament injuries that require surgery are associated with non-contact mechanisms associated with poorly aligned or controlled biomechanical joint forces during running directional changes, sudden stopping-starting, and single leg jump landings $(4,45)$. Across widely diverse sports, it has been shown that non-contact knee injuries are the predominant mechanism for medial collateral ligament, meniscus and anterior cruciate ligament knee injuries. Therefore, devices that enhance dynamic neuromuscular knee control rather than increased mechanical constraints are of primary importance.

\section{CONCLUSIONS}

Compared to standard knee sleeve and no knee device conditions, the T:25 device provided better dynamic knee valgus FPPA control and stronger subject perceptions of best overall condition, knee control and sports movement capability.

\section{CONFLICT OF INTERESTS}

The authors declare that they have no conflict of interests.

4. Hewett TE, Myer GD. The mechanistic connection between the trunk, hip, knee, and anterior cruciate ligament injury. Exerc Sport Sci Rev 2011; 39:161-166.

5. Baltaci G, Aktas G, Camci E, Oksuz S, Yildiz S, Kalaycioglu $\mathrm{T}$. The effect of prophylactic knee bracing on performance: balance, proprioception, coordination, and muscular power. Knee Surg Sports Traumatol Arthrosc 2011; 19:1722-1728.

6. Bodendorfer BM, Arnold NR, Shu HT, Leary EV, Cook JL, Gray AD, Guess TM, Sherman SL. Do neoprene sleeves and prophylactic knee braces affect neuromuscular control and cutting agility? Phys Ther Sport 2019; 39:23-31. 
7. Bottoni G, Herten A, Kofler P, Hasler M, Nachbauer W. The effect of knee brace and knee sleeve on the proprioception of the knee in young non-professional healthy sportsmen. Knee 2013; 20:490-492.

8. Erickson BJ, Harris JD, Fillingham YA, Frank RM, Bush-Joseph CA, Bach BR Jr, Cole BJ, Verma NN. Anterior cruciate ligament reconstruction practice patterns by NFL and NCAA football team physicians. Arthroscopy 2014;30:731-738.

9. Smith SD, Laprade RF, Jansson KS, Arøen A, Wijdicks CA. Functional bracing of ACL injuries: Current state and future directions. Knee Surg Sports Traumatol Arthrosc 2014;22:1131-1141.

10. Greene DL, Hamson KR, Bay RC, Bryce CD. Effects of protective knee bracing on speed and agility. Am J Sports Med 2000;28:453-459.

11. Osternig LR, Robertson RN. Effects of prophylactic knee bracing on lower extremity joint position and muscle activation during running. Am J Sports Med 1993;21:733-737.

12. Styf J. The effects of functional knee bracing on muscle function and performance. Sports Med 1999;28:77-81.

13. Selkowitz DM, Beneck GJ, Powers CM. Comparison of electromyographic activity of the superior and inferior portions of the gluteus maximus muscle during common therapeutic exercises. J Orthop Sports Phys Ther 2016;46:794-799.

14. Stecco A, Gilliar W, Hill R, Fullerton B, Stecco C. The anatomical and functional relation between gluteus maximus and fascia lata. J Bodywork Movement Ther 2013;17:512-517.

15. Topical Gear Website. https://compressioninmotion.com/ pages/t25-knee

16. Jones D, Tillman SM, Tofte K, Mizner RL, Greenberg S, Moser MW, Chmielewski TL. Observational ratings of frontal plane knee position are related to the frontal plane projection angle but not the knee abduction angle during a step-down task. J Orthop Sports Phys Ther 2014;44:973-978.

17. Mukaka MM. A guide to appropriate use of correlation coefficient in medical research. Malawi Med J 2012;24:69-71.

18. Flandry F, Hunt JP, Terry GC, Hughston JC. Analysis of subjective knee complaints using visual analog scales. Am J Sports Med 1991;19:112-118.

19. Wilson RC, Jones PW. A comparison of the visual analogue scale and modified Borg scale for the measurement of dyspnoea during exercise. Clin Sci 1989;76:277-282.

20. Hawker GA, Mian S, Kendzerska T, French M. Measures of adult pain: Visual Analog Scale for Pain (VAS Pain), Numeric Rating Scale for Pain (NRS Pain), McGill Pain Questionnaire (MPQ), Short-Form McGill Pain Questionnaire (SF-MPQ), Chronic Pain Grade Scale (CPGS), Short Form-36 Bodily Pain Scale (SF-36 BPS), and Measure of Intermittent and Constant Osteoarthritis Pain (ICOAP). Arthritis Care \& Research, 2011;63:S240-S252.

21. Giotis D, Tsiaras V, Ristanis S, Zampeli F, Mitsionis G, Stergiou N, Georgoulis AD. Knee braces can decrease tibial rotation during pivoting that occurs in high demanding activities. Knee Surg Sports Traumatol Arthrosc 2011;19:1347-1354.

22. Hanzlíkováa I, Richards J, Tomsac M, Chohanb A, Mayb K, Smékala D, Selfe J. The effect of proprioceptive knee bracing on knee stability during three different sport related movement tasks in healthy subjects and the implications to the management of Anterior Cruciate Ligament (ACL). Gait Posture 2016;48:165-170
23. Sinclair JK, Vincent H, Richards JD. Effects of prophylactic knee bracing on knee joint kinetics and kinematics during netball specific movements. Phys Ther Sport 2017;23:93-98.

24. Marchini A, Lauermann SP, Minetto MA, Massazza G, Maffiuletti NA. Differences in proprioception, muscle force control and comfort between conventional and new-generation knee and ankle orthoses. J Electromyogr Kinesiol 2014;24:437-444.

25. Kaminski TW, Perrin DH. Effect of prophylactic knee bracing on balance and joint position sense. J Athl Train 1996; 31:131136.

26. Ewing KA, Begg RK, Galea MP, Lee PV. Effects of prophylactic knee bracing on lower limb kinematics, kinetics, and energetics during double-leg drop landing at 2 heights. Am J Sports Med 2016;44:1753-1761.

27. Hobara H, Hashizume S, Kobayashi Y. Effects of prophylactic ankle and knee braces on leg stiffness during hopping. Open Access J Sports Med 2017;8:107-112.

28. Mortaza N, Ebrahimi I, Jamshidi AA, Abdollah V, Kamali M, Abu Baker W, Abas W, Azuan N, Osman A. The effects of a prophylactic knee brace and two neoprene knee sleeves on the performance of healthy athletes: A crossover randomized controlled trial. PLoS ONE 2012:7; e50110.

29. Grace TG, Skipper BJ, Newberry JC, Nelson MA, Sweetser ER, Rothman ML. Prophylactic knee braces and injury to the lower extremity. J Bone Joint Surg Am 1988;70:422-427.

30. Pietrosimone BG, Grindstaff TL, Linens SW, Uczekaj E, Hertel J. A systematic review of prophylactic braces in the prevention of knee ligament injuries in collegiate football players. J Athl Train 2008;43:409-415.

31. Salata MJ, Gibbs AE, Sekiya JK. The effectiveness of prophylactic knee bracing in American football: A systematic review. Sports Health 2010;2:375-379.

32. Rishiraj N, Taunton JE, Lloyd-Smith R, Woollard R, Regan W, Clement DB. The potential role of prophylactic/functional knee bracing in preventing knee ligament injury. Sports Med 2009:39:937-960.

33. Giotis D, Paschos NK, Zampeli F, Pappas E, Mitsionis G, Georgoulis AD. Bracing can partially limit tibial rotation during stressful activities after anterior crucial ligament reconstruction with a hamstring graft. Orthop Traumatol Surg Res 2016;102:601-606.

34. Giotis D, Zampeli F, Pappas E, Mitsionis G, Papadopoulos $\mathrm{P}$, Georgoulis AD. Effects of knee bracing on tibial rotation during high loading activities in anterior cruciate ligament-reconstructed knees. Arthroscopy 2013;29:1644-1652.

35. Hanzlíková I, Richards J, Hébert-Losier K, Smékal D. The effect of proprioceptive knee bracing on knee stability after anterior cruciate ligament reconstruction. Gait Posture 2019;67:242-247.

36. Lowe WR, Warth RJ, Davis EP, Bailey L. Functional bracing after anterior cruciate ligament reconstruction: A systematic review. J Am Acad Orthop Surg 2017;25:239-249.

37. Peoples AT, Miller TK, Moskal JT, Queen RM. Hop testing symmetry improves with time while wearing a functional knee brace in anterior cruciate ligament reconstructed knees. Clin Biomech 2019; 70:66-71.

38. Rodriguez-Merchan EC. Knee bracing after anterior cruciate ligament reconstruction. J Orthop Surg 2016;39: e602-e609. 
39. Yang X-g, Feng J-t, He X, Wang G, Hu Y-cheng. The effect of knee bracing on the knee function and stability following anterior cruciate ligament reconstruction: A systematic review and meta-analysis of randomized controlled trials. Orthop Traumatol Surg Res 2019.

40. Martinek V, Friederich NF. To brace or not to brace? How effective are knee braces in rehabilitation? Orthopade 1999;28:565-570.

41. Naik AA, Das B, Kamat V. Avoid post operative bracing to reduce ACL rerupture rates. Europ J Orthop Surg Traumatol 2019.

42. Grob K, Manestar M, Filgueira L, Ackland T, Gilbey H, Kuster MS. New insight in the architecture of the quadriceps tendon. J Exp Orthop 2016;3:32.

43. Khayambashi K, Ghoddosi N, Straub RK, Powers CM. Hip muscle strength predicts noncontact anterior cruciate ligament injury in male and female athletes: A prospective study. Am J Sports Med 2016;44:355-361.

44. Balachandar V, Marciniak J-L, Wall O, Balachandar C. Effects of the menstrual cycle on lower-limb biomechanics, neuromuscular control, and anterior cruciate ligament injury risk: A systematic review. Muscles Ligaments Tendons J 2017;7(1):136-146.

45. McLean SG, Walker K, Ford KR, Myer GD, Hewett TE, van den Bogert AJ. Evaluation of a two dimensional analysis method as a screening and evaluation tool for anterior cruciate ligament injury. Br J Sports Med 2005;39:355-362.

46. Zhang LY, Negyesi J, Okuyama T, Tanaka M, Hortobagyi T, Nagatomi R. Position of compression garment around the knee affects healthy adults' knee joint position sense acuity. Hum Movement Sci 2019;67:102519. 